\title{
Expansion of the Analytical System of Measuring Service Effectiveness by Customer Type to Include Repeat Analysis
}

\author{
Shuhei Haraga, Michiko Tsubaki, and Takafumi Suzuki
}

\begin{abstract}
Customer heterogeneity is an important characteristic of the service field. Accordingly, it is essential to analyse service effectiveness by customer type in each service store. Previous research proposed an analytical system for measuring service effectiveness by customer type. The user of this system classifies customers into types based on the customers' needs, preferences, and purchasing behaviour, and compares the characteristics between types. Users of the system can then analyse service effectiveness by customer type using the conditional probability distribution. The system was developed to show the conditional probability distribution on the preconditions of both the ordered variable and the categorical variable, which are frequently seen in service field survey questionnaires. The system's usefulness was verified by analysing the satisfaction data of a city library as an applied example. In this research, we expand this system for analysing service effectiveness by customer type into a system that allows analysis of the repeat data at two time points. Furthermore, we analyse more general purchase data from the service field to verify the value of the findings on service satisfaction through the use of this system.
\end{abstract}

Index Terms-Analytical system of measuring service effectiveness by customer type, change of conditional probability, classifying customers, repeat analysis.

\section{INTRODUCTION}

Recently, the percentage of the world economy represented by the service field is very large; the service field represents $70 \%$ or more of the GDP in many countries.

It is important, then, to analyse the service effects. In addition, it is beneficial for customers and service providers to compare and analyse what kinds of factors effect or do not effect what kinds of customer types, because customer heterogeneity of service effects is very large [1]-[3].

Because individual differences in the educational and learning effects for students are large, [4] developed a system for analysing educational and learning effects by student type, in consideration of individual differences (heterogeneity). Further, [5] expanded the system proposed by [4], and proposed and developed their analytical system of measuring service effectiveness by customer type. The system classifies service customers by their preferences, characteristics, needs, purchasing behaviors, and so on based on their questionnaire answers. It can then analyse service effects by customer type

Manuscript received July 9, 2013; revised September 22, 2013.

Shuhei Haraga, Michiko Tsubaki, and Takafumi Suzuki are with the Department of Informatics, The University of Electro-Communications, Tokyo, JAPAN (e-mail: h1330055@edu.cc.uec.ac.jp, tsubaki@se.uec.ac.jp, s1230044@edu.cc.uec.ac.jp). using conditional probability.

The system was developed to show the conditional probability distribution on the preconditions of both the ordered variable and the categorical variable, which are frequently seen in service field survey questionnaires.

However, the system proposed by [5] did not take repeat analyses over time into consideration. When we analyse service effectiveness, it is important to compare and analyse the change by type over time [6], [7]. In this research, we expanded and developed the analytical system for measuring service effectiveness by customer type into a system that allows analysis of change based on the repeat data measurements at two time points.

Furthermore, in this research, we apply the proposed system to the cosmetic service data offered by the Social Science Japan Data Archive (SSJDA) collected from the POLA Research Institute of Beauty \& Culture. We show the usefulness of the findings for change in customer type and change in service effectiveness based on the factors which improve customer satisfaction by customer type according to this system.

\section{OUTLINE OF THE EXPANSION OF THE ANALYTICAL SYSTEM OF MEASURING SERVICE EFFECTIVENESS BY CUSTOMER TYPE TO INCLUDE REPEAT ANALYSIS}

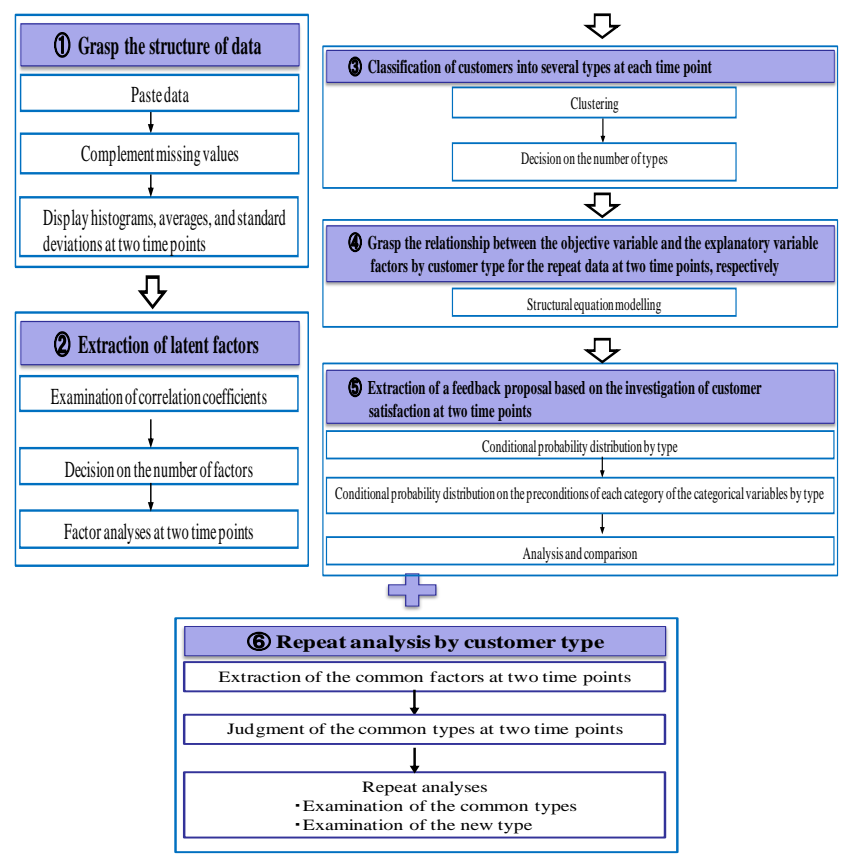

Fig. 1. Outline of the expansion of the analytical system of measuring service effectiveness by customer type to include repeat analysis. 
In this research, we expand the analytical system proposed by [5] for measuring service effectiveness by customer type to allow repeat analysis, as outlined in Fig. 1.

1) First, we grasp the two data structures respectively using basic statistics.

2) Next, we carry out the factor analysis for the repeat data at two time points and understand the customer structure for the service based on customers' characteristics, needs, expectations, purchasing behaviors, and so on.

3) We perform Ward-based clustering of customers based on the factor score acquired using factor analysis, and classify the customers into several types for the repeat data at two time points.

4) We grasp the relationship between the objective variable and the explanatory variable factors by customer type using structural equation modeling for the repeat data at two time points.

5) We analyse service effectiveness by type, comparing the conditional probability distributions of the objective variable on the preconditions of the ordered or categorical explanatory variables by type, and extract the feedback proposal about customer satisfaction by type.

6) In addition, in this research, we extract the common factors that appear in two-factor analysis carried out at two time points. Furthermore, we compare the results of the clustering at each time point using the obtained common factors. We propose to refer to the correlation coefficient between the factor scores of each of the two types, and examine whether the same customer type appears at two time points. If the same customer type appears at two time points, we analyse the change in service effectiveness based on the factors which improve customer satisfaction by customer type. Otherwise, if a new type appears at the second time point, we analyse the change of type as a special type (new type) at that time point.

7) Furthermore, in order to develop the proposed system, we use RExcel, which is an interface program using $\mathrm{R}$ as an add-on to MS Excel [8]-[10]. Using RExcel, we conducted all calculations in $\mathrm{R}$, which is the most sophisticated statistical software available, and all outputs and interfaces in MS Excel, which is a tool in widespread use including among non-experts. Therefore, this system has the reliability of R for statistical analysis and the usability of MS Excel. The developed system thus enables users who lack high-level statistical knowledge and techniques to analyse service effectiveness by customer type easily.

\section{GRASPING THE CUSTOMER STRUCTURE FOR THE} SERVICE AND CLASSIFICATION OF CUSTOMERS INTO TYPES

In this system, we conduct factor analysis for the data at each time point, and classify customers into types by clustering customers using the factor scores. In this chapter, we explain these analytical processes while showing the analysis of the cosmetic service data as an applied example.

\section{A. Grasping the Customer Structure for the Service}

First, we decide on the number of factors using the scree plot, and carry out the factor analysis using the promax rotation after the principal factor analysis based on the decided number of factors.

TABLE I: FACTOR LOADINGS FOR EACH ITEM AT THE FIRST TIME POINT

\begin{tabular}{|c|c|c|c|}
\hline & $\begin{array}{l}\text { First Factor: Degree of importance of } \\
\text { the treatments araalable at the } \\
\text { specialty store }\end{array}$ & $\begin{array}{l}\text { Second Factor. Frequency of } \\
\text { makeup use }\end{array}$ & $\begin{array}{l}\text { Eighth Factor: } \\
\text { Annual income }\end{array}$ \\
\hline Age & -0.032 & 0.069 & 0.375 \\
\hline Degree of importance of casual clothes & -0.124 & .0 .030 & -0.022 \\
\hline Degree of importance of clothes for business & 0.187 & 0.043 & 0.207 \\
\hline Degree of importance of accessories such as jewellery & 0.108 & -0.052 & 0.012 \\
\hline Degree of importance of bags & -0.013 & -0.095 & 0.079 \\
\hline Degree of importance of shoes & -0.072 & -0.075 & 0.079 \\
\hline Degree of importance of restaurant meals & -0.083 & 0.037 & 0.151 \\
\hline Degree of importance of meals at home & -0.305 & 0.007 & -0.075 \\
\hline Degree of importance of sweets, luxury goods & -0.145 & -0.015 & -0.110 \\
\hline Degree of importance of health food & 0.181 & 0.025 & -0.065 \\
\hline Degree of mportance of house & 0.047 & -0.039 & 0.083 \\
\hline Degree of importance of interior & -0.095 & 0.007 & -0.073 \\
\hline Degree of importance of gardening & 0.034 & -0.011 & -0.082 \\
\hline Degree of importance of trips & -0.022 & 0.047 & 0.315 \\
\hline Degree of importance of mories, theatregoing, concerts & -0.072 & -0.019 & 0.179 \\
\hline $\begin{array}{l}\text { Degree of importance of art appreciation, such as visiting an } \\
\text { art gallery or the museum }\end{array}$ & -0.086 & .0 .050 & 0.141 \\
\hline $\begin{array}{l}\text { Degree of importance of hobbies such as ceramic art or } \\
\text { photography }\end{array}$ & 0.047 & 0.002 & -0.078 \\
\hline Degree of importance of reading & -0.148 & -0.049 & 0.039 \\
\hline Degree of importance of learning & -0.010 & -0.018 & -0.085 \\
\hline Degree of importance of playing spotts & 0.187 & -0.015 & 0.094 \\
\hline Degree of importance of watching sports & 0.145 & .0 .021 & 0.134 \\
\hline Degree of importance of skincare cosmetics & 0.019 & 0.319 & -0.132 \\
\hline Degree of importance of makeup cosmetics & 0.057 & 0.418 & -0.136 \\
\hline $\begin{array}{l}\text { Degree of importance of beauty supplements, beauty health } \\
\text { food }\end{array}$ & 0.350 & 0.171 & -0.138 \\
\hline Degree of importance of hair salons & 0.204 & 0.202 & 0.019 \\
\hline Degree of importance of beauty treatment salons & 0752 & -0.003 & 0.095 \\
\hline Degree of importance of beauty spas with stone saunas & 0.656 & 0.011 & 0.056 \\
\hline Degree of importance of nail salons & 0.770 & -0.049 & -0.014 \\
\hline Degree of importance of beanty clinics & 0.918 & -0.095 & -0.005 \\
\hline Degeree of importance of minor cosmetic surgery & 0.784 & -0.116 & -0.014 \\
\hline Degree of importance of diet & 0.264 & -0.033 & -0.029 \\
\hline Degree of importance of reading of Intemet sites & -0.123 & -0.050 & 0.026 \\
\hline $\begin{array}{l}\text { Degree of importance of participation in Intemet sites, } \\
\text { neluding winting a blog }\end{array}$ & 0.060 & -0.071 & -0.095 \\
\hline Degree of importance of conversation using a mobile phone & 0.146 & 0.048 & 0.105 \\
\hline Degree of mportance of email using a mobile phone & 0.026 & 0.103 & 0.090 \\
\hline Degree of importance of volunter activity & 0.185 & -0.048 & -0.062 \\
\hline Degree of importance of pets & 0.100 & -0.070 & -0.019 \\
\hline Skincare of the face & -0.020 & 0.575 & -0.042 \\
\hline Makeup use in everyday life & -0.071 & 0.818 & 0.169 \\
\hline Frequency of primer for makeup & -0.049 & 0.589 & 0.028 \\
\hline Frequency of control colour & 0.160 & 0.083 & -0.052 \\
\hline Frequency of foundation & -0.116 & 0.813 & 0.173 \\
\hline Frequency of eye shadowr & -0.051 & 0.595 & -0.024 \\
\hline Frequency of eyebrows & -0.029 & 0.431 & .0 .034 \\
\hline Frequency of mascara & 0.000 & 0.440 & -0.112 \\
\hline Frequency of lip liner & 0.146 & 0.093 & -0.038 \\
\hline Frequency of lipstick & 0.010 & 0.491 & 0.340 \\
\hline Frequency of lip gross & 0.075 & 0.265 & -0.132 \\
\hline Impression of the amount of money spent on cosmetics & 0.150 & 0.059 & 0.091 \\
\hline Household annual incone & -0.051 & 0.055 & 0.562 \\
\hline Individual annual income & 0.133 & 0.024 & 0.592 \\
\hline One month's pocket money & -0.002 & 0.092 & 0.459 \\
\hline
\end{tabular}

See Fig. 2. We use parallel analysis, which adopts the number of factors just before the polygonal line of eigenvalues and the parallel line cross. As a result, we compared the factor analysis results with factor numbers 8,9 , and 10 , and decided that 8 is the number of factors at the first time point.

We show partial results of factor analysis at the first time point in Table I.

From Table I, we named the first factor at the first time 
point 'The degree of importance of the treatments available at the specialty store' because the factor loadings for the degree of importance of the beauty treatments available at salons, beauty spas with stone saunas, nail salons, beauty clinics, and minor cosmetic surgery are high. We named the second factor 'the frequency of makeup use' because the factor loadings for factors such as the frequency of makeup use in everyday life and the frequency of using foundation are high. Similarly, we named the eight factors as in Table II.

TABLE II: NAMES OF FACTORS AT THE FIRST TIME POINT

\begin{tabular}{|l|l|}
\hline & \multicolumn{1}{|c|}{ Factor's name } \\
\hline First Factor & $\begin{array}{l}\text { Degree of importance of the treatments available at the } \\
\text { specialty store }\end{array}$ \\
\hline Second Factor & Frequency of makeup use \\
\hline Third Factor & Degree of importance of fashion \\
\hline Fourth Factor & Degree of importance of appearing polished \\
\hline Fifth Factor & Degree of importance of communications \\
\hline Sixth Factor & Degree of importance of skincare cosmetics \\
\hline Seventh Factor & Age and degree of importance of house \\
\hline Eighth Factor & Annual income \\
\hline
\end{tabular}
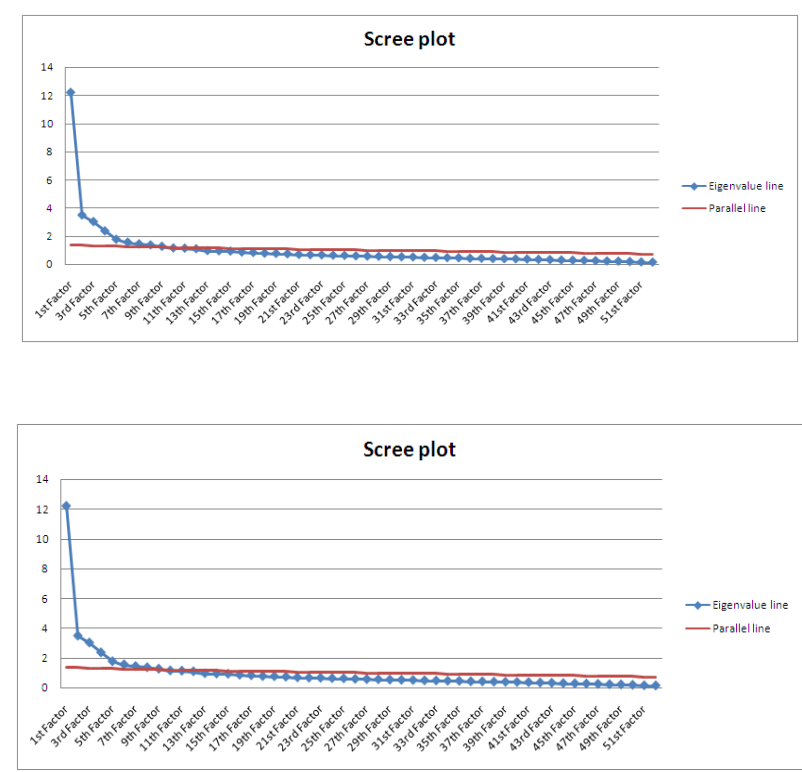

Fig. 2. The scree plot at the first time point.

TABLE III: FACTOR SCORE AVERAGES AND THE NUMBER OF PERSONS By TYPE AT THE FIRST TIME POINT

\begin{tabular}{|l|r|r|r|r|r|}
\hline Five clusters at the first time point & Group 1 & Group 2 & Group 3 & Group 4 & Group 5 \\
\hline Degree of importance of the treatments available at the specialty store & -0.030 & 0.061 & 1.964 & -0.696 & -0.437 \\
\hline Frequency of makeup use & 0.407 & 0.191 & 0.800 & -0.455 & -0.700 \\
\hline Degree of importance of fashion & 0.810 & 0.042 & 1.401 & -0.920 & -0.807 \\
\hline Degree of importance of appearing polished & 0.220 & 0.201 & 1.441 & -1.155 & -0.413 \\
\hline Degree of importance of communications & 0.743 & -0.115 & 1.390 & -0.747 & -0.605 \\
\hline Degree of importance of skincare cosmetics & 0.089 & 0.403 & 0.971 & -1.263 & -0.360 \\
\hline Age and degree of importance of house & -0.373 & 0.427 & 0.971 & -1.011 & -0.128 \\
\hline Annual income & -0.462 & 0.462 & 0.176 & -0.924 & 0.154 \\
\hline Number of persons & 306 & 520 & 134 & 191 & 349 \\
\hline
\end{tabular}

\begin{tabular}{|c|c|c|c|c|c|}
\hline Six clusters at the first time point & Group 1 & Group 2 & Group 3 & Group 4 & Group 5 \\
\hline Degree of importance of the treatments available at the specialty store & -0.030 & -0.017 & 1.964 & -0.696 & -0.437 \\
\hline Frequency of makeup use & 0.407 & 0.264 & 0.800 & -0.455 & -0.700 \\
\hline Degree of importance of fashion & 0.810 & -0.084 & 1.401 & -0.920 & -0.807 \\
\hline Degree of importance of appearing polished & 0.220 & 0.028 & 1.441 & -1.155 & -0.413 \\
\hline Degree of importance of communications & 0.743 & -0.239 & 1.390 & -0.747 & -0.605 \\
\hline Degree of importance of skincare cosmetics & 0.089 & 0.194 & 0.971 & -1.263 & -0.360 \\
\hline Age and degree of importance of house & -0.373 & 0.172 & 0.971 & -1.011 & -0.128 \\
\hline Annual income & -0.462 & 0.258 & 0.176 & -0.924 & 0.154 \\
\hline Number of persons & 306 & 392 & 134 & 191 & 349 \\
\hline
\end{tabular}

\section{A. Classification of Customers into Types}

Next, we classify the customers into types by clustering customers using the factor scores. In Table III, we show the average values of factor scores and the number of people by type when we choose five and six groups at the first time point. ('Groups' are how we classify customers using the clustering. After we interpret the characteristics of each group, we call them 'types'.) Therefore, 'groups' are used in all displays in the system, as in Table III and Fig. 3.

In this research, we adopted six clusters. From Table III, group 2 when 5 clusters are used is separated into group 2 and group 6 when the clusters are separated into 6 clusters. We consider six clusters to be valid because the factor scores of the sixth, seventh, and eighth factors have differences between group 2 and group 6 when there are six clusters. Group 6 has 128 persons, which is the minimum number of persons in each group in Table III. Furthermore, we consider that there is no problem in adopting six clusters from the viewpoint of the number of persons when we carry out structural equation modelling and the conditional probability analysis as the next analyses.

We classify customers into types at each time point in this way.

\section{PROPOSAL FOR THE EXPANSION TO INCLUDE REPEAT ANALYSIS OF SERVICE EFFECTIVENESS B Y CUSTOMER TYPE}

In this chapter, we explain the proposal for the expansion of the analytical system of measuring service effectiveness by customer type to include repeat analysis.

\section{A. Extraction of the Common Factors at Two Time Points}

In this research, we introduce a function that allows users of this analytical system to extract common factors easily by displaying the variables with factor loadings greater than the standard value at each time point once the user determines 'the standard' of the factor loadings in this system and presses the decision button. We choose the common factors for each time point by using the function, and determine the 
common factors' names at two time points (see Fig. 4).

We extracted eight common factors at two time points using the cosmetic service data.

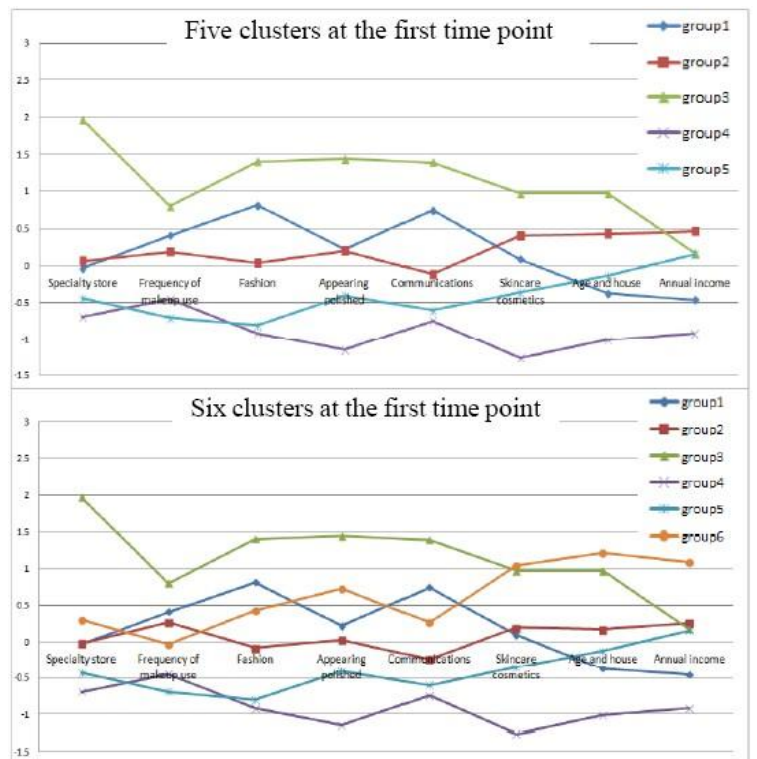

Fig. 3. Average plots of factor scores at the first time point

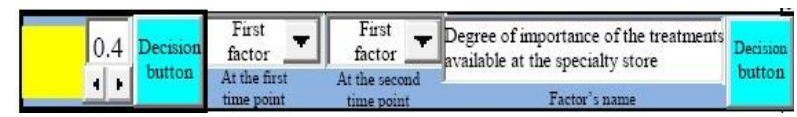

At the first time point

\begin{tabular}{|c|c|c|c|}
\hline & First Factor & & Second Factor \\
\hline Degree of importance of beauty treatment salons & 0.752 & Skincare of the face & 0.575 \\
\hline Degree of importance of beauty spas with stone saunas & 0.566 & Makeup use in everyday life & 0.818 \\
\hline \begin{tabular}{|l|l|} 
Degree of impotance of nali salons \\
\end{tabular} & 0.77 & Frequency of primer for makeup & 0.589 \\
\hline Degree of importance of beauty clinics & 0.918 & Frequency of foundation & 0.813 \\
\hline \multirow[t]{4}{*}{ Degree of importance of minor cos metic surgery } & 0.784 & Frequency of eye shadow & 0.595 \\
\hline & & Frequency of eybbrows & 0.431 \\
\hline & & Frequency of mascara & 0.4 \\
\hline & & Frequency of lipstick & 0.491 \\
\hline
\end{tabular}

\begin{tabular}{l} 
At the second time point \\
\hline
\end{tabular}

Fig. 4. Extraction of the common factors.

\section{B. Determination of the Common Types at Two Time Points}

The table and plots of averages of the common factor scores by type at each time point are displayed for the determination of the common types in Fig. 5. The figure also shows the correlation coefficients between the factors scores of each of the two types to determine the common types introduced in this research. It is easy for the user to determine the common types because the table and plots of averages of the common factor scores by type at each time point are devised to be displayed in order of factors of first time point. If common types exist at the first and second time points, we choose the numbers of those types and move them to the summary sheet to describe the types' characteristics. We carry out the repeat analysis by type by examining the characteristics of the common types and filling in the relevant boxes.

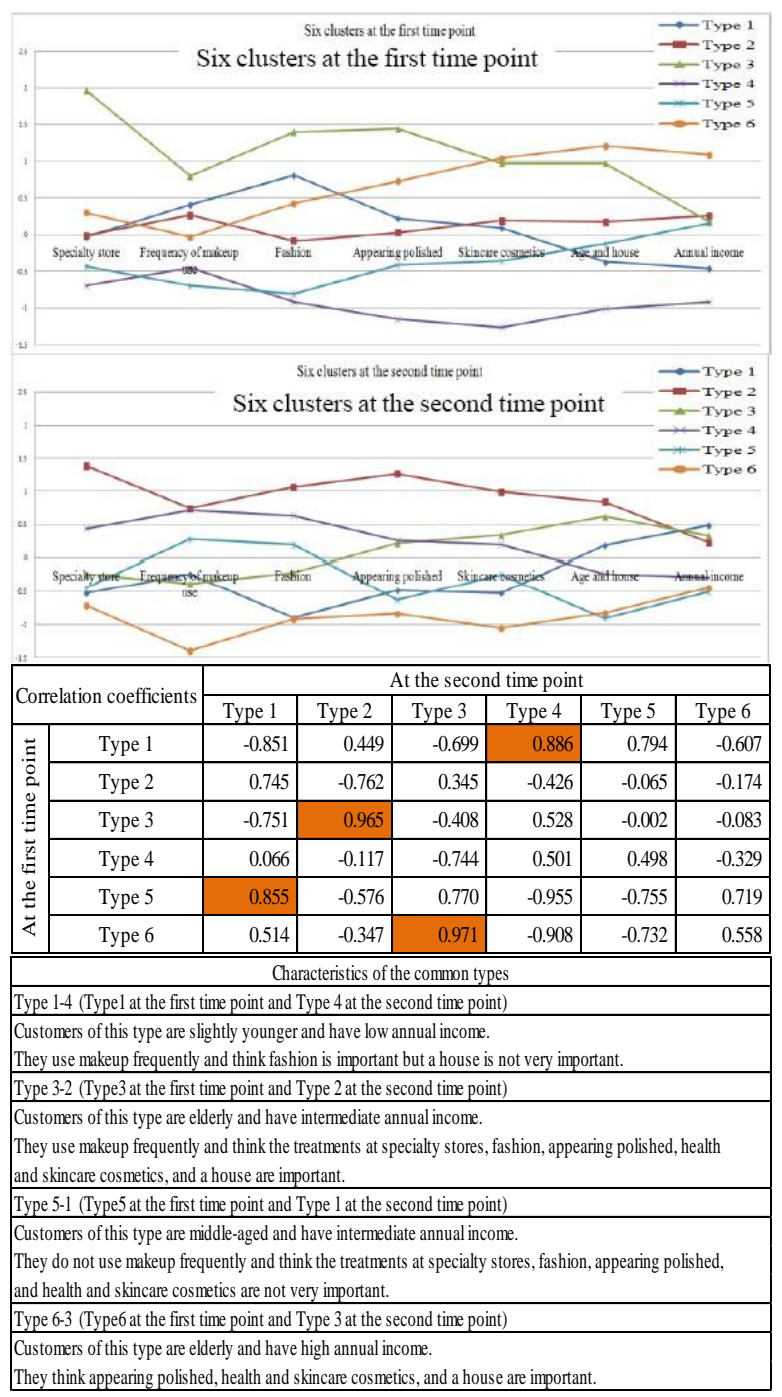

Fig. 5. Determination of the common types at two time points.

We examined this applied data using the table and plots of the averages of the common factor scores by type at each time point and the correlation coefficients between the factor scores of each of the two types. As a result, there are four types that we can judge to be the same at the first and second time points, as shown in Table IV.

\section{Repeat Analysis of the Conditional Probabilities}

\section{1) Examination of the common types}

The importance for the marketing of the retail trade is changing from "the acquisition" of new customers to "the maintenance" of excellent customers. Reference [11] indicates that we need to clarify purchase behaviours of excellent customers and suggest a merchandising and a layout of sales floor matched the needs of excellent customers. In the repeat analysis of the conditional probabilities, we focus on the common types as excellent customers (repeaters), grasp a

behaviour characteristics, and consider efficient purchase strategies.

If common types exist at the two time points, we carry out repeat analysis of the service effectiveness as follows:

- Comparison between the distributions of the response variable at the two time points;

- Comparison between the distributions of the explanatory variables, which affect the response 
variable;

- Comparison between the conditional distributions of the response variable on the precondition of the explanatory variables at the two time points;

We developed the system to analyse the three items above.

For (1), the distributions of the degree of total satisfaction with makeup do not differ between time points because these distributions centre on 3 (a little satisfied) at each time point, as shown in Table $\mathrm{V}$.

For (2), from Table $\mathrm{V}$, for the explanatory variable 'makeup use in everyday life', the percentage of persons who answered category 5 (I use makeup almost every day) and 6 (I use makeup every day) at the second time point increased in comparison with the percentage at the first time point. As to 'the degree of importance of e-mail on a mobile phone', we consider the tendency for this explanatory variable to be a small decrease, because the distribution at the second time point is centred on categories 3 (a little important) and 4 (important), and the percentage of the persons who answered category 5 (very important) at the first time point was higher than it was for the second time point.

TABLE IV: DETERMINATION OF THE COMMON TYPES AT TWO TIME POINTS

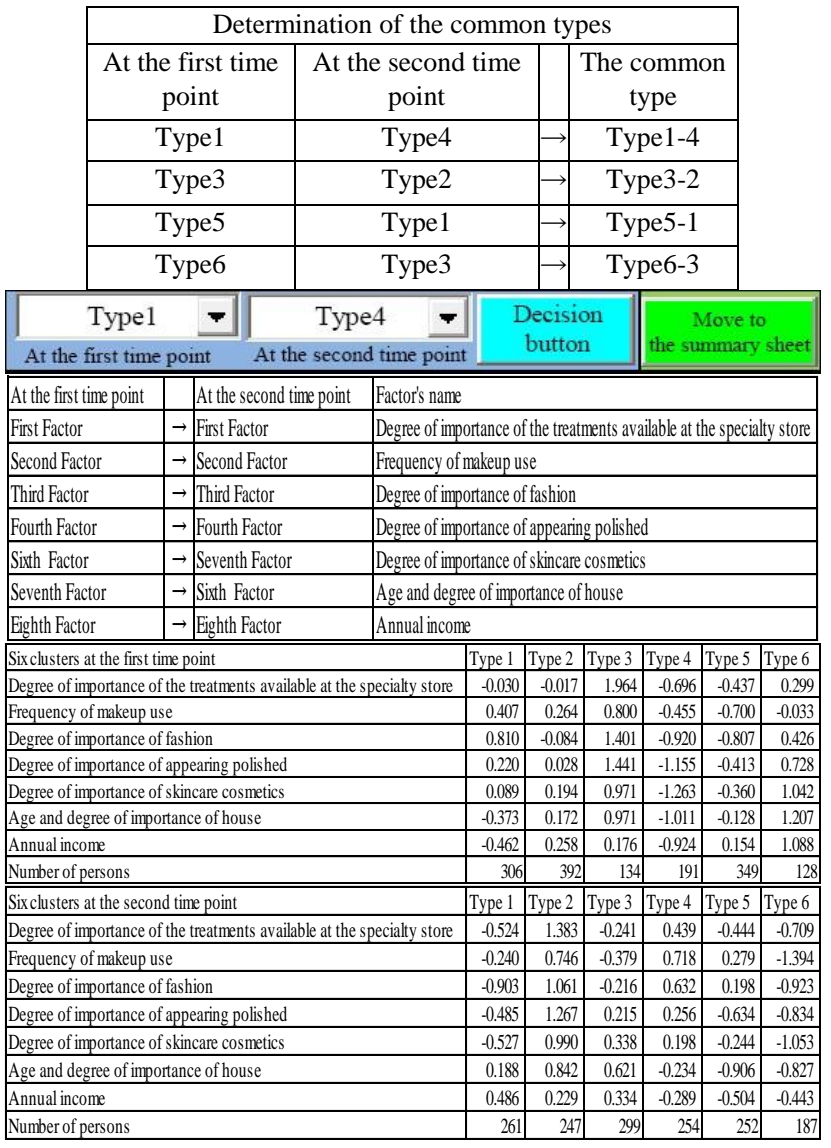

For (3), we explain the case of Type 1-4 (Type 1 at the first time point and Type 4 at the second time point) as an example. At the first time point, the people who answered categories 4, 5 , and 6 on the precondition of 'makeup use in everyday life', that is, the people who use makeup more frequently, have a higher average conditional distribution of the degree of total satisfaction with makeup. However, at the second time point, people who answered in all categories for the precondition 'makeup use in everyday life,' have a high average conditional distribution of the degree of total satisfaction with makeup. Thus, we find a change from the first to the second time point. However, at both time points, the people who answered in high categories for the precondition of 'the degree of importance of e-mail on a mobile phone' have a higher average conditional distribution of the degree of total satisfaction with makeup.

TABLE V: CONDITIONAL PROBABILITIES OF TYPE 1 AT THE FIRST TIME POINT AND TyPE 4 AT THE SECOND TIME POINT Degree of total satisfaction with makeup

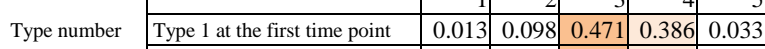
\begin{tabular}{|l|l|l|l|l|l|}
\hline Type 4 at the second time point & 0.008 & 0.051 & 0.504 & 0.362 & 0.075 \\
\hline
\end{tabular}

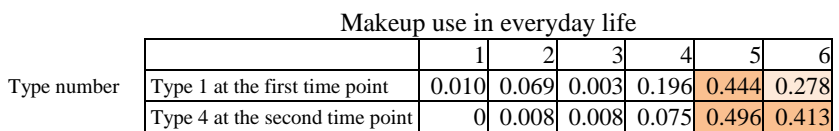
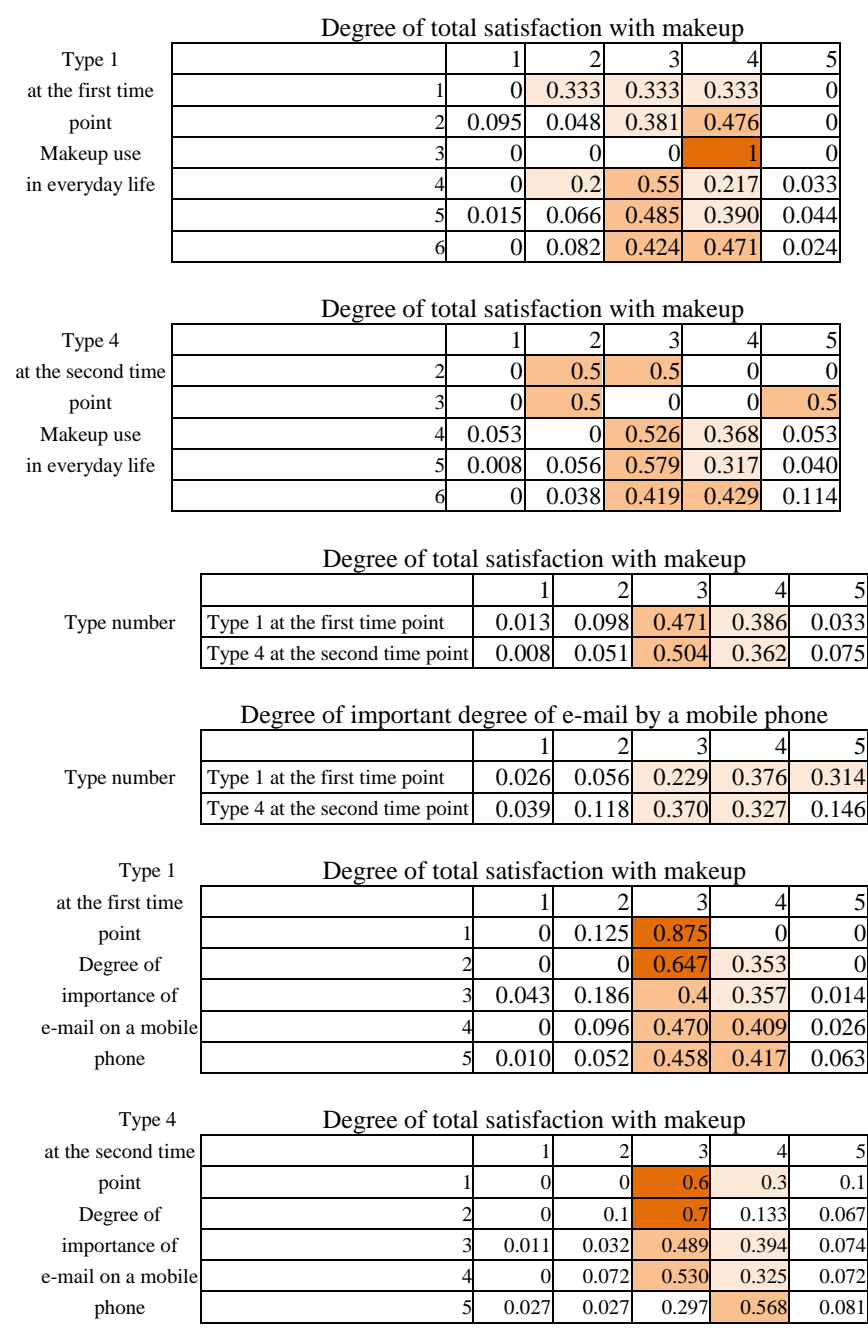

Because Type 1-4 increased their degree of total satisfaction with makeup as they answered in higher categories for the degree of importance of e-mail on a mobile phone, have a young average age, use makeup frequently, and are interested in cosmetics, the selling strategy of cosmetic shops for Type 1-4 should, for example, include announcing shop information using social networking services (SNS). In addition, because the annual incomes of people in Type 1-4 are a little low, we consider it efficient to give these customers valuable information by distributing coupons and announcing sales with the aim of increasing the 
frequency with which they come to the shop and purchase cosmetics.

\section{2) Examination of the new customer type}

If new customer types exist at the second time point, we analyse them as follows:

- Examination of the distribution of the response variable of the new customer type at the second time point;

- Examination of the distribution of the explanatory variables which affect the response variable in the new customer type;

- Examination of the conditional distribution of the response variable on the precondition of the explanatory variable in the new customer type at the second time point;

TABLE VI: Conditional PRoBabilities of TyPes 5 AND 6 AT THE SECOND TIME POINT

Degree of total satisfaction with makeup

\begin{tabular}{c|r|r|r|r|r|r|}
\multicolumn{1}{c}{} & \multicolumn{5}{c}{ Degree of total satisfaction with makeup } \\
\cline { 2 - 7 } & & 1 & 2 & 3 & 4 & 5 \\
\cline { 2 - 7 } & 5 & 0.016 & 0.060 & 0.520 & 0.381 & 0.024 \\
\cline { 2 - 7 } Type number & 6 & 0.021 & 0.182 & 0.497 & 0.230 & 0.070 \\
\cline { 2 - 6 } & & & &
\end{tabular}

\begin{tabular}{c|r|r|r|r|r|r|}
\multicolumn{1}{c}{} & \multicolumn{6}{c}{ Degree of importance of skincare products } \\
\cline { 2 - 7 } & & 1 & 2 & 3 & 4 & 5 \\
Type number & 5 & 0 & 0.016 & 0.440 & 0.401 & 0.143 \\
\cline { 2 - 7 } at the second time point & 6 & 0.262 & 0.310 & 0.326 & 0.096 & 0.005 \\
\cline { 2 - 6 } & & & & & &
\end{tabular}

\begin{tabular}{|c|c|c|c|c|c|c|}
\hline \multirow{6}{*}{$\begin{array}{l}\text { Type } 5 \\
\text { at the second time point } \\
\text { Degree of importance of } \\
\text { skincare products }\end{array}$} & \multicolumn{6}{|c|}{ Degree of total satisfaction with makeup } \\
\hline & & 1 & 2 & 3 & 4 & \\
\hline & 2 & 0 & 0.25 & 0.5 & 0.25 & 0 \\
\hline & 3 & 0.018 & 0.072 & 0.550 & 0.351 & 0.009 \\
\hline & 4 & 0.020 & 0.059 & 0.515 & 0.376 & 0.030 \\
\hline & 5 & 0 & 0 & 0.444 & 0.5 & 0.056 \\
\hline
\end{tabular}

\begin{tabular}{|c|c|c|c|c|c|c|}
\hline \multirow{5}{*}{$\begin{array}{l}\text { Type } 6 \\
\text { at the second time point } \\
\text { Degree of importance of }\end{array}$} & \multicolumn{6}{|c|}{ Degree of total satisfaction with makeup } \\
\hline & & 1 & 2 & 3 & 4 & \\
\hline & 1 & 0.020 & 0.265 & 0.449 & 0.204 & 0.061 \\
\hline & 2 & 0.034 & 0.155 & 0.552 & 0.172 & 0.086 \\
\hline & 3 & 0.016 & 0.164 & 0.492 & 0.279 & 0.049 \\
\hline & 4 & 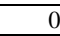 & 0.111 & 0.5 & 0.278 & 0.111 \\
\hline & & 0 & 0 & 0 & 1 & 0 \\
\hline
\end{tabular}

\begin{tabular}{c|c|r|r|r|r|r|}
\multicolumn{1}{c}{} & \multicolumn{1}{c}{ Degree of total satisfaction with makeup } \\
\cline { 2 - 7 } & & 1 & 2 & 3 & 4 & 5 \\
\cline { 2 - 7 } Type number & 5 & 0.01 & 0.06 & 0.52 & 0.38 & 0.02 \\
& & 6 & 0 & 0 & 1 & 4 \\
\cline { 2 - 7 } at the second time point & 0.02 & 0.18 & 0.49 & 0.23 & 0.07 \\
\cline { 2 - 8 } & 6 & 1 & 2 & 0 \\
\cline { 2 - 7 }
\end{tabular}

\begin{tabular}{c|c|r|r|r|r|r|}
\multicolumn{1}{c}{} & \multicolumn{6}{c}{ Degree of importance of makeup products } \\
\cline { 2 - 7 } & & 1 & 2 & 3 & 4 & 5 \\
\cline { 2 - 7 } Type number & 5 & 0.00 & 0.06 & 0.46 & 0.39 & 0.07 \\
& & 8 & 0 & 0 & 3 & 9 \\
\cline { 2 - 7 } at the second time point & 0.47 & 0.33 & 0.18 & 0.01 & 0 \\
\cline { 2 - 7 } & & 1 & 2 & 7 & 1 & 0 \\
\cline { 2 - 7 }
\end{tabular}

\begin{tabular}{|c|c|c|c|c|c|c|}
\hline \multirow{3}{*}{$\begin{array}{l}\text { Type } 5 \\
\text { at the second time point }\end{array}$} & \multicolumn{6}{|c|}{ Degree of total satisfaction with makeup } \\
\hline & & 1 & 2 & 3 & 4 & 5 \\
\hline & 1 & 0 & 0 & 0 & 1 & 0 \\
\hline \multirow{6}{*}{ Degree of importance of } & 2 & 0.06 & 0.06 & 0.53 & 0.26 & 0.06 \\
\hline & & 7 & 7 & 3 & 7 & 7 \\
\hline & 3 & 0.00 & 0.06 & 0.60 & 0.32 & 0 \\
\hline & & 0.02 & 0.05 & 0.47 & 0.42 & 0.03 \\
\hline & 4 & 0 & 1 & 5 & 4 & 0 \\
\hline & 5 & 0 & 0.1 & 0.3 & 0.5 & 0.1 \\
\hline
\end{tabular}

\begin{tabular}{|c|c|c|c|c|c|c|}
\hline \multirow[b]{2}{*}{ Type 6} & \multicolumn{6}{|c|}{ Degree of total satisfaction with makeup } \\
\hline & & 1 & 2 & 3 & 4 & 5 \\
\hline \multirow[t]{2}{*}{ at the second time point } & 1 & 0.02 & 0.19 & 0.48 & 0.22 & 0.06 \\
\hline & & $\frac{3}{0.3}$ & 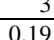 & $\frac{9}{0.53}$ & $\frac{1}{0.17}$ & $\begin{array}{r}8 \\
0.06\end{array}$ \\
\hline Degree of importance of & 2 & 2 & 4 & 2 & 7 & 5 \\
\hline \multirow{3}{*}{ makeup products } & 3 & 0 & 0.14 & 0.45 & 0.31 & 0.08 \\
\hline & & 0 & & $\frac{1}{0 .}$ & 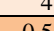 & $\frac{6}{0}$ \\
\hline & 4 & 0 & 0 & 0.5 & 0.5 & 0 \\
\hline
\end{tabular}

Types 5 and 6 at the second time point are the new customer types which have special characteristics at the second time point. These two types are young and have the low annual income. However, the frequency of makeup use and the degree of importance of fashion are high for customer Type 5. In contrast, the frequency of makeup use and the degree of importance of fashion are generally low for Type 6 . See Table VI.

For (1), the degree of total satisfaction with makeup for Types 5 and 6 are distributed centering on categories 3 and 4; the degree of total satisfaction for both types tends to be a little high.

For (2), the degree of importance of skincare products and makeup products are distributed centring on category 3 for type 5 . In contrary, for type 6 , the mode of each distribution is category 1 (not important), and their degree of importance of cosmetic products tends to be low.

For (3), from the conditional distribution of Table VI, we find that both Types 5 and 6 increase the degree of total satisfaction with makeup at the second time point, as they answered with higher categories for the degree of importance of skincare products. Furthermore, we find that at the second time point, Types 5 and 6 increased their degree of total satisfaction with makeup, as they answered with a higher category for the degree of importance of makeup products, with an exception of category 1 of Type 5. Furthermore, because the average age of Type 5 is young and their annual income is low, we consider it efficient for cosmetic shops to sell cheap products with the aim of increasing the frequency with which this customer type enters the shop and purchases cosmetics.

We also compared Type 5 and Type 6; it is important to examine which type should get priority in terms of elaborating the purchasing strategy.

\section{CONCLUSION}

In this research, we expanded the analytical system of measuring service effectiveness by customer type developed by [5] to allow repeat analysis. With this new, expanded system, we can analyse service effectiveness by customer type in parallel at two time points: first to grasp the structure of the data and then to extract latent factors at each time point and introduce the function to extract the common factors by comparing the latent factors at each time point and the function of the repeat analyses by types in the sixth step. For the repeat analysis by customer type, we expanded the system by adding the following functions:

- Extraction of the common factors at two time points;

- Judgement of the common types at two time points;

- Examination of the common types;

- Examination of the new customer type;

As a result, we can analyse the service effects in consideration of the heterogeneity of customers at each shop. Then, we showed that we can get valuable findings based on the repeat change of common customer types at two time points and the examination of new customer types at the second time point.

\section{REFERENCES}

[1] B. Stauss, K. Engelmann, A. Kremer, and A. Luhn, Service Science, Springer, 2008. 
[2] M. Kondo, A Guide to Marketing Research, 3rd edition, Nikkei Inc., 2004.

[3] C. Lovelock and J. Wirtz, Services Marketing, 7th edition, Prentice Hall, 2010.

[4] M. Tsubaki, T. Oya, and Y. Tokutomi, "A proposal of the system for analyzing the educational and learning effects by student type," Journal of the Japan Society of Educational Information, vol. 28, no. 3, pp. 23-24, November, 2013.

[5] Y. Tokutomi and M. Tsubaki, "Proposal of analytical system of the service effectiveness by customer type," in Proc. the 27th Annual Meeting of the Japan Society for Science Policy and Research Management, 1C03, 2012.

[6] Y. Huzikoshi, The Mathematical Principle of Repeated Data Analysis, Asakura Publishing Co., Ltd., 2009.

[7] S. Kitagawa, A Guide to Time Series Analysis, Iwanami Shoten, 2005.

[8] R. M. Heiberger and E. Neuwirth, R through Excel, Springer, 2010.

[9] B. S. Everitt and T. Hothorn, A Handbook of Statistical Analyses Using $R$, 2nd edition, CRC Press, 2010.

[10] M. Kim, The Data Science by R, Morikita Publishing Co., Ltd., 2010.

[11] B. P. Woolf, "Customers specific marketing: The new power in retailing," Teal Books, 1996.

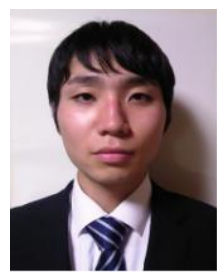

Shuhei Haraga was born in Tokyo, Japan, in 1991. He is a master's course student in the Department of Informatics at the University of Electro-Communications. He received his BS in the Department of Systems Engineering at the University of Electro-Communications. His current research interest is Service Science.

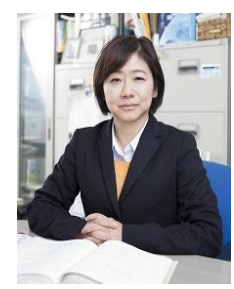

Michiko Tsubaki is a professor in the Department of Informatics at The University of Electro-Communications, Japan. She received her BS in Applied Mathematics and her MS and DS in Management Science from Science University of Tokyo, Japan. She was a Visiting Scholar at Oxford University in 1992. Her recent research interests is Service Science. She was the Associate Editor of the Journal of the Japanese Society for Quality Control (JSQC) from 1990 to 1997, the Associate Editor of the Journal of the Japan Industrial Management Association from 2000 to 2001 and the Associate Editor of the Journal of the Japanese Society of Applied Statistics from 2000 to 2008. She has been a Program Committee Member of the World Multi-Conference on Systemics, Cybernetics and Informatics since 2005 and a Program Committee Member of the International Symposium on Academic Globalization since 2007.

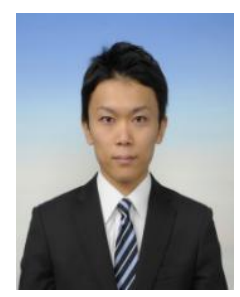

Takafumi Suzuki was born in Yamagata, Japan, in 1989. He is a master's course student in the Department of Informatics at the University of Electro-Communications. He received his BS in the Department of Systems Engineering at the University of Electro-Communications. His current research interest is Service Science. 